\title{
OPORTUNIDADES DE APRENDER MATEMÁTICA NO BRASIL, CHILE E ESTADOS UNIDOS
}

PAULA LOUZANO ARIANE FARIA DOS SANTOS

\section{RESUMO}

Este trabalho utiliza dados do Programme for International Student Assessment (PISA) 2012 do Brasil, Chile e Estados Unidos para analisar a oportunidade de os alunos de diferentes níveis socioeconômicos em aprender matemática, medida pela exposição a conceitos e problemas dessa disciplina. Os alunos brasileiros apresentam grandes desvantagens em relação aos demais na cobertura curricular e mesmo os alunos mais ricos apresentam baixa probabilidade de exposição curricular frente aos seus colegas dos outros países. Além disso, a probabilidade de nunca terem sido expostos a conceitos e problemas matemáticos aumenta à medida que os conceitos ficam mais complexos, assim como cresce a desigualdade entre os mais pobres e os mais ricos. Portanto, não só observamos grandes desigualdades entre ricos e pobres em suas oportunidades de aprender matemática, mas também baixa exposição curricular dos alunos brasileiros de modo geral.

PALAVRAS-CHAVE OPORTUNIDADE DE APRENDIZAGEM - PISA • ENSINO DE MATEMÁTICA • CURRÍCULO. 


\section{OPORTUNIDADES DE APRENDER MATEMÁTICAS EN BRASIL, CHILE Y ESTADOS UNIDOS}

RESUMEN

Este trabajo utiliza datos del Programme for International Student Assessment (PISA) 2012 de Brasil, Chile y Estados Unidos para analizar la oportunidad de que alumnos de distintos niveles socioeconómicos aprendan matemáticas, medida por la exposición a conceptos y problemas de tal disciplina. Los alumnos brasileños presentan grandes desventajas en relación a los demás en la cobertura curricular e incluso los alumnos más ricos presentan baja probabilidad de exposición curricular con relación a sus colegas de los demás países. Por otra parte, la probabilidad de que nunca hayan sido expuestos a conceptos y problemas matemáticos aumenta a medida que los conceptos se hacen más complejos, así como crece la desigualdad entre los más pobres y los más ricos. Por lo tanto, no solo observamos grandes desigualdades entre ricos y pobres en sus oportunidades de aprender matemáticas, sino también una baja exposición curricular de los alumnos brasileños en general.

PALABRAS CLAVE OPORTUNIDAD DE APRENDIZAJE • PISA • ENSEÑANZA DE MATEMÁTICAS • CURRÍCULO.

\section{OPPORTUNITIES TO LEARN MATHEMATICS IN BRAZIL, CHILE AND THE UNITED STATES}

ABSTRACT

This paper uses data from the Program for International Student Assessment (PISA) 2012 of Brazil, Chile and the United States to analyze the opportunity of students from different socioeconomic backgrounds to learn Mathematics, assessed by the exposure to concepts and problems of this discipline. The Brazilian students present major disadvantages compared to the others in terms of curriculum coverage and even the richest students have a low probability of curriculum exposure compared with their peers from other countries. In addition, the likelihood of never having been exposed to mathematical concepts and problems increases as the concepts become more complex, and as inequality increases between the poorest and the richest. Therefore, not only do we observe large inequalities between rich and poor regarding their opportunities to learn Mathematics, but also a low curriculum exposure of Brazilian students as a whole.

KEYWORDS LEARNING OPPORTUNITY • PISA • TEACHING OF MATHEMATICS • CURRICULUM. 


\section{INTRODUÇÃO}

Pesquisas sobre eficácia escolar vêm demonstrando que, dentre os fatores intraescolares, os elementos que constituem o ensino e as práticas pedagógicas - também conhecidos pela literatura como fatores de Opportunity to Learn (OTL) - são os que mais impactam a aprendizagem dos alunos, principalmente os de baixo nível socioeconômico (MCDONNELL, 1995; SAMMONS, 1995; SIMIELLI, 2015).

Os estudos sobre os fatores de OTL englobam desde a formação, experiência e envolvimento do professor com a aprendizagem, como sua capacidade de gerir a classe e o conteúdo ministrado a fim de garantir OTL a todos os alunos. Especificamente, as pesquisas sobre OTL têm destacado a relevância do currículo para a melhora do aprendizado dos alunos, o que envolve tanto o cumprimento desse ao longo do ano escolar, como o aprofundamento do conteúdo curricular por meio de diferentes estratégias e práticas pedagógicas que desenvolvam no aluno o raciocínio mais profundo da disciplina (BOALER, 2001; CARNOY, 2003, 2007; LOUZANO, 2007; RIVKIN; SCHIMAN, 2015). Porém, uma das 
dificuldades para realização de estudos dessa natureza é a insuficiência de dados que possibilitem esse tipo de análise, principalmente no que diz respeito a variáveis ligadas ao ensino, às práticas de sala de aula e ao currículo (SCHMIDT; MAIER, 2009).

Este artigo usa os dados do Programme for International Student Assessment (PISA) para analisar os fatores de OTL relacionados à cobertura curricular de matemática no Brasil, Chile e Estados Unidos. É notório que os alunos brasileiros apresentam resultados piores. Por exemplo, 70,2\% dos alunos brasileiros estão abaixo do nível 2 do PISA (são seis níveis no total), contra $49,3 \%$ do Chile e apenas $29,4 \%$ dos alunos dos Estados Unidos. Na medida em que as pesquisas associam parte desse problema a questões curriculares, este estudo comparado visa a calcular a probabilidade de os alunos de vários níveis socioeconômicos serem expostos a diferentes conceitos e problemas matemáticos ao longo de sua trajetória escolar, especificamente vinculados às quatro categorias de conteúdos de matemática avaliadas pelo PISA: Mudanças e Relações; Espaço e Forma; Quantidade; e Incerteza e Dados.

Este artigo estrutura-se em quatro partes. Primeiro, apresenta a revisão de literatura sobre OTL, com foco no tema curricular. Em seguida, introduz a metodologia, com as especificações do modelo logit e dos dados utilizados, e passa para a análise dos resultados obtidos com respeito às probabilidades de exposição dos alunos dos três países aos diferentes conceitos e problemas matemáticos. Finalmente, apresenta a conclusão, que sintetiza os achados da pesquisa e sugere como eles podem trazer contribuições para as políticas educacionais.

\section{O CONCEITO DE OTL}

O conceito de OTL tem se modificado ao longo do tempo. Sua origem, na década de 1960, vinculava esse conceito exclusivamente ao tempo de instrução oferecido aos alunos com o objetivo de obter determinado aprendizado, levando-se em consideração as características do indivíduo e dos processos 
1 HUSEN, Torsten et al. International study of achievement in mathematics, a comparison of twe/ve countries. International project for the evaluation of educational achievement. IEA (Phase 1). Washington: ERIC Clearinghouse, 1967

2 TRAVERS, Kenneth J.; GARDEN Robert A.; ROSIER, M. Introduction to the study. In: ROBITAILLE, David F.; GARDEN, Robert A. (Ed.). The IEA study of mathematics II: contexts and outcomes of school mathematics. New York: Pergamon, 1988. p. 1-16. a que ele foi exposto (CARROLL, 1963). A partir das pesquisas internacionais comparadas sobre ensino de matemática First International Mathematics Survey (1963-1967) e Second Internacional Mathematics Study (1976-1982) -, que investigaram as relações entre os resultados dos alunos e o conteúdo curricular ministrado nas escolas, o conceito de OTL foi redefinido como uma medida que buscava compreender se "alunos tiveram ou não oportunidades de aprender um tópico particular ou estudar como resolver um tipo específico de problema” (HUSEN et al., 1967, p. 162-163 ${ }^{1}$ apud BURSTEIN, 1993). Esses estudos sobre o ensino de matemática partiam de dois instrumentos: (i) o resultado em provas realizadas por alunos com questões sobre conteúdos de matemática e (ii) o questionário aplicado aos professores com questões sobre OTL em matemática. Coletaram-se, ainda, informações sobre o currículo a fim de selecionar conteúdos de matemática comuns a todos os sistemas avaliados e construir provas que permitissem comparações entre eles. (TRAVERS; GARDEN; ROSIER, $1988^{2}$ apud MCDONNELL, 1995, p. 318).

A intenção desses estudos era tentar compreender as relações entre a aprendizagem dos alunos e as OTL que eles tiveram em sala de aula. No caso desses trabalhos, o conceito de OTL era operacionalizado como o conteúdo curricular efetivamente ministrado aos alunos. Desse modo, buscava-se entender se (i) o currículo prescrito nos documentos oficiais continha os conteúdos adequados; (ii) o currículo implementado em sala de aula cobria realmente todos os pontos e em que profundidade; e (iii) se o desempenho do aluno nas avaliações tinha relação com o currículo desenvolvido em aula (ZAKARYAN, 2011).

Essas pesquisas permitiram compreender aspectos relevantes sobre as OTL em matemática oferecidas pelos diferentes sistemas educacionais. $\mathrm{O}$ primeiro aspecto diz respeito à diferença entre o que é prescrito pelo currículo e o que é efetivamente implementado em sala de aula. O segundo refere-se às diferenças na organização do currículo. Por exemplo, os pesquisadores encontraram que, enquanto em alguns países havia ênfase em alguns tópicos matemáticos, como, por exemplo, álgebra no Japão e geometria e frações na França 
e na Bélgica, nos Estados Unidos havia grande diversidade de tópicos com menor profundidade e grande fragmentação em sua abordagem (MCDONNELL, 1995; ROBITAILLE, 1989). Finalmente, McDonnell (1995, p. 308) encontrou diferenças nas oportunidades oferecidas nos diferentes sistemas educacionais. Por exemplo, enquanto no Japão havia grande homogeneidade entre as salas de aulas analisadas na cobertura de conteúdos relacionados à álgebra, nos Estados Unidos havia grande desigualdade entre as escolas na cobertura dessa área da matemática.

Os resultados desses estudos influenciaram o debate sobre como os processos de ensino e a exposição ao currículo podem fazer diferença na aprendizagem do aluno. Em decorrência, seguiu-se um conjunto de trabalhos que procuravam entender o que acontecia durante o processo de ensino das diferentes disciplinas e áreas, a fim de compreender quais eram as OTL oferecidas aos alunos nas escolas e salas de aula (HERMAN; KLEIN; ABEDI, 2000; MULLENS, 1999; PORTER, 1998; PORTER et al., 1993, 2000; SCHMIDT, 1983; SCHMIDT et al., 2001; STEVENSON; STIGLER, 1992). Esses trabalhos, em geral, buscam compreender o tempo gasto em cada tópico do currículo, com que profundidade é tratado, a qualidade dos materiais utilizados no ensino e as práticas e estratégias desenvolvidas pelo professor para cada conteúdo ministrado, ou seja, as relações entre ensino e aprendizagem (EVERTSON, 1983; HIEBERT; GROUWS, 2007; MACCINI; GAGNON, 2000).

Os resultados de tais estudos levaram à intensificação do debate sobre as desigualdades presentes nos sistemas educacionais, na medida em que evidenciaram que grupos minoritários e mais pobres tinham acesso a uma porcentagem menor do currículo e a atividades que demandavam processos cognitivos menos complexos. Chamado por Haberman (1991) de "pedagogia da pobreza", estudos como o do autor em escolas urbanas nos Estados Unidos evidenciaram que o ensino nesses locais não dava oportunidade para as crianças terem acesso a atividades que as permitissem pensar sobre um problema matemático, analisar diferentes formas de resolução, além de realizar outros processos cognitivos 
mais complexos, já que se restringiam a atividades de fácil resolução.

Um dos desafios desse tipo de pesquisa é a dificuldade de medir o conceito de OTL. Schmidt e Maier (2009) argumentam que, apesar de ser um conceito bastante simples exposição do aluno ao currículo -, não significa que seja fácil medi-lo. Alguns estudos focam no currículo implementado e perguntam aos professores e/ou aos estudantes, por meio de questionários ou registros individuais, "se" e "em que medida" determinado conteúdo curricular foi apresentado na sala de aula (ROWAN; CAMBURN; CORRENTI, 2004). Além disso, outras pesquisas pediram a especialistas em currículo para analisar como os conteúdos estavam sendo cobertos nos documentos curriculares, tais como programas, planos de aula e normativas, focando no currículo pretendido. Em muitos casos, o conteúdo ensinado foi analisado de duas maneiras: a apresentação ou não do tópico em sala de aula e o nível de demanda cognitiva exigida a partir do que foi apresentado. Além disso, do ponto de vista do sistema, alguns estudos buscaram analisar coerência, rigor e foco curricular (SCHMIDT; MAIER, 2009).

\section{OTL NO PISA}

Em seu modelo de análise, o PISA utiliza a definição de OTL referente à exposição do aluno ao currículo e operacionaliza o conceito a partir da perspectiva do estudante. Nesse sentido, o PISA pergunta aos alunos de diferentes países sobre sua exposição a determinados conteúdos, tópicos e conceitos matemáticos diretamente ou por meio de problemas (descritos ou explicitamente apresentados) para que apontem se e em que medida realizaram esse tipo de atividade em suas aulas. No entanto, a ideia de OTL presente no PISA não se refere apenas ao tempo de exposição ao currículo, mas também, e não menos importante, aos tópicos e tipo de matemática apresentada aos alunos de diferentes países.

O objetivo central do PISA é avaliar se os jovens de 15 anos desenvolveram os conhecimentos e as habilidades de vida necessários para se adaptar às constantes mudanças do 
mundo (RAY; MARGARET, 2002) e, por essa razão, não adota uma matriz curricular como referência para as áreas avaliadas. No entanto, a fim de criar uma estrutura comum para os diferentes países analisados, classifica o conhecimento em matemática em três aspectos inter-relacionados: (i) os processos matemáticos que descrevem as capacidades utilizadas pelos alunos para conectar o contexto do problema com o conteúdo e, assim, resolver o problema; (ii) o conteúdo matemático que classifica os diferentes assuntos da disciplina em áreas para uso nos itens da avaliação; e (iii) os contextos que correspondem aos lugares em que os processos e conteúdos matemáticos estão localizados (PEÑA-LÓPEZ, 2012).

O conteúdo matemático - objeto central deste artigo - ${ }^{3}$ é classificado pelo PISA em quatro áreas ou "grandes ideias" que nutrem os ramos em crescimento da matemática (STEEN, 1990; ORGANISATION FOR ECONOMIC CO-OPERATION AND DEVELOPMENT - OECD, 2013 ${ }^{4}$ apud PIACENTINI; MONTICONE, 2016): (i) Mudanças e Relações; (ii) Espaço e Forma; (iii) Quantidade; e (iv) Incerteza e Dados. Tais tópicos visam a caracterizar o conjunto de conteúdos matemáticos centrais para a disciplina e ilustram as áreas que orientam o desenvolvimento de itens para o teste de proficiência do PISA. Além disso, buscam refletir

[...] as semelhanças encontradas nas expectativas estabelecidas por uma série de países e jurisdições educacionais [...] e trazem evidências não apenas do que é ensinado nas salas de aula de matemática nesses países, mas também como indicadores do que os países entendem como importantes conhecimentos e habilidades para preparar os alunos para se tornarem bons cidadãos. (PEÑA-LÓPEZ, 2012, p. 33, tradução nossa) ${ }^{5}$

O PISA trata, na categoria Mudanças e Relações, de habilidades e conteúdos relacionados a funções e álgebra, incluindo expressões algébricas, equações e desigualdades, representações tabulares e gráficas. Já a geometria é a base essencial para a categoria Espaço e Forma e o PISA trabalha com ampla gama de fenômenos encontrados em toda parte em nosso mundo visual e físico: padrões, propriedades de
3 Não detalhamos os outros aspectos, pois não serão objeto de análise no presente trabalho.

4 ORGANISATION FOR ECONOMIC CO-OPERATION AND DEVELOPMENT. PISA 2012 results: ready to learn. Students' engagement, drive and self-beliefs. Paris: OECD Publishing, 2013. v. 3.

5 Texto original: "These specific topics reflect commonalities found in the expectations set by a range of countries and educational jurisdictions [...] are viewed as evidence not only of what is taught in mathematics classrooms in these countries but also as indicators of what countries view as important knowledge and skills for preparing students of this age to become constructive, engaged and reflective citizens". 
objetos, posições e orientações, representações de objetos, decodificação e codificação de informações visuais, navegação e interação dinâmica com formas reais e representações.

A categoria Quantidade trabalha com aspectos do raciocínio quantitativo - como o sentido do número, múltiplas representações de números, cálculo mental, estimativa e avaliação da razoabilidade dos resultados -, que são a essência da alfabetização matemática. Assim, essa categoria aplica o conhecimento dos números e das operações numéricas em uma ampla variedade de configurações. Finalmente, a categoria Incerteza e Dados inclui as áreas curriculares tradicionais de probabilidade e estatística que entregam meios formais de descrever, modelar e interpretar fenômenos de incerteza e de fazer inferências (PEÑA-LÓPEZ, 2012).

\section{METODOLOGIA}

\section{DESCRIÇÃO DOS DADOS}

Este trabalho utiliza dados de avaliação do PISA 2012 de três países - Brasil, Chile e Estados Unidos -, assim como os questionários contextuais respondidos pelos alunos participantes da avaliação. O intuito é operacionalizar, por meio dos dados do PISA, os fatores de OTL relacionados à cobertura curricular da disciplina de matemática, analisando a probabilidade de alunos de diferentes níveis socioeconômicos desses três países serem expostos a uma gama de conceitos e problemas matemáticos ao longo de sua trajetória escolar.

O PISA é uma avaliação realizada pela OECD cujo objetivo é analisar os sistemas educacionais a partir de testes de habilidades e conhecimentos de estudantes de 15 anos de idade em mais de 60 países. As avaliações ocorrem a cada três anos e são constituídas por três áreas do conhecimento - Leitura, Matemática e Ciências - sendo que, a cada edição do programa, é dada ênfase a uma dessas áreas. Em 2012, o PISA teve como foco a área de matemática.

A avaliação é composta por um teste de conhecimento para as três áreas e questionários contextuais focados apenas na área de destaque de cada ano. Os questionários trazem questões sobre as características dos alunos e de sua família, 
da trajetória e hábitos escolares dos estudantes e de como são as práticas de ensino e aprendizagem da escola e dos professores da área de destaque da edição do PISA daquele ano. Os questionários são respondidos pelos alunos, professores, escolas e pais. ${ }^{6}$

O presente artigo utiliza as questões do questionário contextual do aluno, especificamente os itens que abordam a frequência de exposição a tipos de atividade e familiaridade com conceitos da área de matemática ao longo da trajetória escolar do aluno. Para a construção do nível socioeconômico dos alunos, utilizou-se o "índice de status econômico, social e cultural” fornecido pelo próprio PISA. A partir desse índice, os alunos de cada país foram classificados em 10 percentis, dos quais foram utilizados, neste artigo, apenas os com menor $\left(1^{\circ}\right.$ percentil) e maior $\left(10^{\circ}\right.$ percentil) nível socioeconômico de cada país, a fim de representar o grupo dos $10 \%$ mais pobres e dos $10 \%$ mais ricos, respectivamente, utilizados na análise. A respeito da proficiência no PISA, utilizou-se o desempenho geral dos alunos na área de matemática.

A escolha pelos dados do PISA $2012^{7}$ justifica-se na medida em que é a principal avaliação mundial em larga escala, possibilitando a comparação entre países tanto em relação ao desempenho dos estudantes quanto às OTL disponíveis em cada país para alunos de diferentes grupos sociais.

Por fim, cabe esclarecer as razões da escolha de comparar o Brasil com os demais países analisados. No caso do Chile, a escolha baseia-se no fato de que é um país latino-americano que compartilha com o Brasil questões geográficas e socioeconômicas. Além disso, o Chile tem desempenho em matemática, no PISA, melhor que o Brasil e passou por intensa reforma curricular nos últimos anos, podendo trazer informações relevantes para nosso debate educacional. No caso dos Estados Unidos, apesar de ser um país muito mais desenvolvido que o Brasil, apresentam imensas desigualdades sociais e educacionais. É também um país de grande extensão territorial e diversidade cultural, cuja organização administrativa é federalista, guardando semelhanças com o caso brasileiro. Além disso, os Estados Unidos realizaram um processo recente de reforma curricular na maioria dos
6 Embora haja todos esses tipos de questionário no PISA, não são todos os países que aplicam todos os tipos.

7 A base de dados do PISA 2012 tem 485.490 respostas, sendo 19.204 para o Brasil, 6.856 para o Chile e 4.978 para os Estados Unidos. 
estados, com implementação de padrões curriculares nacionais (Common Core), podendo, assim como no caso do Chile, apoiar o debate educacional brasileiro.

\section{REGRESSÃO MULTIVARIADA}

Com o intuito de compreender a relação entre o desempenho em matemática no PISA 2012 e a exposição a um conjunto de conceitos matemáticos para então proceder à análise da distribuição dessas oportunidades, realizou-se a regressão multivariada, na qual a variável dependente corresponde à proficiência dos alunos e às variáveis independentes aos conceitos matemáticos. As especificações do modelo e os resultados da regressão estão no apêndice deste artigo. Encontrou-se correlação negativa entre o aluno nunca ter sido exposto aos conceitos/problemas de matemática apresentados e a proficiência em matemática no PISA 2012. Essa evidência foi o ponto de partida para este artigo, uma vez que seu intuito é medir a probabilidade de alunos de diferentes níveis socioeconômicos de distintos países estarem sendo expostos a tais conceitos e problemas matemáticos por meio de seus currículos escolares que guardem algum tipo de associação com o aprendizado dos alunos.

\section{MODELO LOGIT}

Após a análise de correlação efetuada por meio da regressão multivariada, passou-se a analisar a distribuição dos fatores de OTL relacionados à cobertura curricular da disciplina de matemática, utilizando o modelo logit. As especificações do modelo logit e os resultados (em odds ratio) encontram-se no apêndice deste artigo. $\mathrm{O}$ objetivo desse modelo é investigar a probabilidade de os alunos - pertencentes aos $10 \%$ mais pobres e $10 \%$ mais ricos de cada país - terem sido expostos a diferentes conceitos e problemas matemáticos ao longo de sua trajetória escolar. Os modelos desenvolvidos têm como variáveis dependentes os conceitos da área de matemática e exemplos de problemas (Quadro 1) e como variáveis independentes as características dos estudantes, ou seja, (i) o nível socioeconômico dos alunos (classificados em dois grupos - $10 \%$ mais pobres e $10 \%$ mais ricos) e (ii) o país a 
que pertencem esses alunos (Brasil, Chile e Estados Unidos). Por sua vez, para as variáveis dependentes, utilizaram-se a probabilidade de os alunos (i) nunca terem ouvido o termo/nunca terem encontrado esse tipo de problema matemático na sua vida escolar e (ii) conhecerem o termo muito bem e compreenderem seu conceito/frequentemente terem encontrado esse tipo de problema matemático na sua vida escolar. ${ }^{8}$

8 Essa diferença de análise ocorre devido à formulação das alternativas disponíveis no questionário contextual dos alunos.

QUADRO 1 - Conceitos matemáticos analisados no PISA

\begin{tabular}{|l|l|}
\hline \multirow{4}{*}{ MUDANÇAS E RELAÇÕES } & Equação linear \\
\cline { 2 - 3 } & Função quadrática \\
\cline { 2 - 3 } & Função exponencial \\
\cline { 2 - 3 } & Resolver uma equação igual a esta: $3 x+5=17$ \\
\cline { 2 - 3 } & Resolver uma equação igual a esta: $6 x^{2}+5=29$ \\
\cline { 2 - 3 } & Resolver uma equação igual a esta: $2(x+3)=(x+3)(x-3)$ \\
\hline \multirow{5}{*}{ ESPAÇO E FORMA } & Vetores \\
\cline { 2 - 3 } & Cosseno \\
\cline { 2 - 3 } & Polígono \\
\cline { 2 - 3 } & Figura congruente \\
\hline \multirow{3}{*}{ QUANTIDADE } & Radicais \\
\cline { 2 - 3 } & Número racional \\
\cline { 2 - 3 } & Número complexo \\
\hline & Média aritmética \\
\cline { 2 - 3 } & Probabilidade \\
\hline
\end{tabular}

Fonte: Elaboração das autoras.

\section{RESULTADOS}

As seções a seguir apresentam os resultados do modelo logit por meio de gráficos que mostram as probabilidades de exposição aos conceitos e problemas matemáticos analisados neste artigo para os três países e, em cada um, para os $10 \%$ mais ricos $(\bullet)$ e os $10 \%$ mais pobres ( $\boldsymbol{\Delta})$. É importante destacar que todos os gráficos apresentam a probabilidade de os alunos (i) nunca terem escutado cada um dos conceitos - os três gráficos na parte superior - e (ii) conhecerem bem e compreenderem tais ideias matemáticas - os três gráficos 
na parte inferior. As análises irão comparar tanto as disparidades entre os dois grupos sociais em cada país como a diferença entre os três países.

PROBABILIDADE DE ACESSO A CONCEITOS E PROBLEMAS MATEMÁTICOS DA CATEGORIA MUDANÇAS E RELAÇÕES

Na categoria Mudanças e Relações, analisou-se a probabilidade de os alunos terem sido expostos a três conceitos matemáticos pertencentes ao campo da álgebra: (i) equação linear; (ii) função quadrática; e (iii) função exponencial. Em geral, os alunos são expostos primeiro a equações e depois a funções, já que as primeiras envolvem ideias matemáticas mais simples. Além disso, costuma-se expor os alunos, primeiramente, a funções lineares (ou também conhecidas como funções de $1^{\circ}$ grau), depois a funções quadráticas (ou de $2^{\circ}$ grau), para posteriormente apresentá-los a outros tipos de funções, como as exponenciais.

Levando tais características em consideração, podemos observar, no Gráfico 1, que a probabilidade de os alunos nunca terem escutado um termo aumenta à medida que o conceito torna-se mais complexo. Isso significa que a probabilidade de os alunos, nos três países, nunca terem escutado o conceito "função exponencial" durante sua trajetória escolar é maior do que no caso do conceito "equação linear". Por exemplo, enquanto menos de $10 \%$ dos alunos mais pobres dos Estados Unidos afirmaram nunca terem escutado o termo "equação linear", o percentual nesse país sobe para aproximadamente $25 \%$ no caso de "função exponencial".

Além disso, a desigualdade entre os alunos mais pobres e mais ricos em cada país tende a crescer à medida que o conceito torna-se mais complexo. O aumento da "brecha curricular" com o crescimento da complexidade ocorre nos três países, mas é de maior intensidade no Chile e nos Estados Unidos do que no Brasil.

Porém, embora pareça positivo esse menor aumento da "brecha curricular" no Brasil, isso ocorre porque, ao contrário dos Estados Unidos e do Chile, a diferença entre pobres e ricos no Brasil acontece anteriormente, isto é, a desigualdade brasileira já está dada no acesso ao conceito mais simples 
dessa categoria - função linear - enquanto que nos outros dois países a brecha acentua-se em conceitos mais abstratos - a partir de função quadrática, no Chile, e função exponencial, nos Estados Unidos.

Por fim, ao se comparar os três países, os alunos brasileiros dos dois grupos sociais aparecem com as maiores probabilidades de "nunca" terem ouvido sobre os conceitos algébricos, com exceção da comparação com os chilenos em função quadrática. Percebe-se que, em alguns casos, até os alunos mais pobres do Chile e dos Estados Unidos têm menor ou igual probabilidade de nunca terem escutado um termo do que os alunos mais ricos do Brasil. Por exemplo, enquanto aproximadamente $15 \%$ dos alunos mais ricos no Brasil nunca escutaram o termo "equação linear", essa porcentagem é menor que 10\% entre os alunos mais pobres do Chile e dos Estados Unidos.

Seguindo essa tendência, a probabilidade de os alunos responderem "conhecer muito bem e compreender" um conceito diminui quanto mais complexo é o conceito matemático. Por exemplo, enquanto a probabilidade de os alunos mais ricos conhecerem muito bem e compreenderem o termo "equação linear" é de 70\% no Chile e 80\% nos Estados Unidos, no caso de "função exponencial", a probabilidade para esses alunos cai para $20 \%$ e $45 \%$ respectivamente.

O Brasil é novamente uma exceção, pois, no caso dos três conceitos algébricos, a probabilidade de conhecê-los bem e compreendê-los é em torno de $30 \%$ para os alunos mais ricos e $10 \%$ para os mais pobres, ou seja, o ponto inicial (compreensão de equação linear) é bastante baixo quando comparado com Estados Unidos (80\% e 40\%, respectivamente) e Chile ( $70 \%$ e $30 \%$, respectivamente). 
GRÁFICO 1 - Probabilidade de exposição aos conceitos matemáticos da categoria Mudanças e Relações

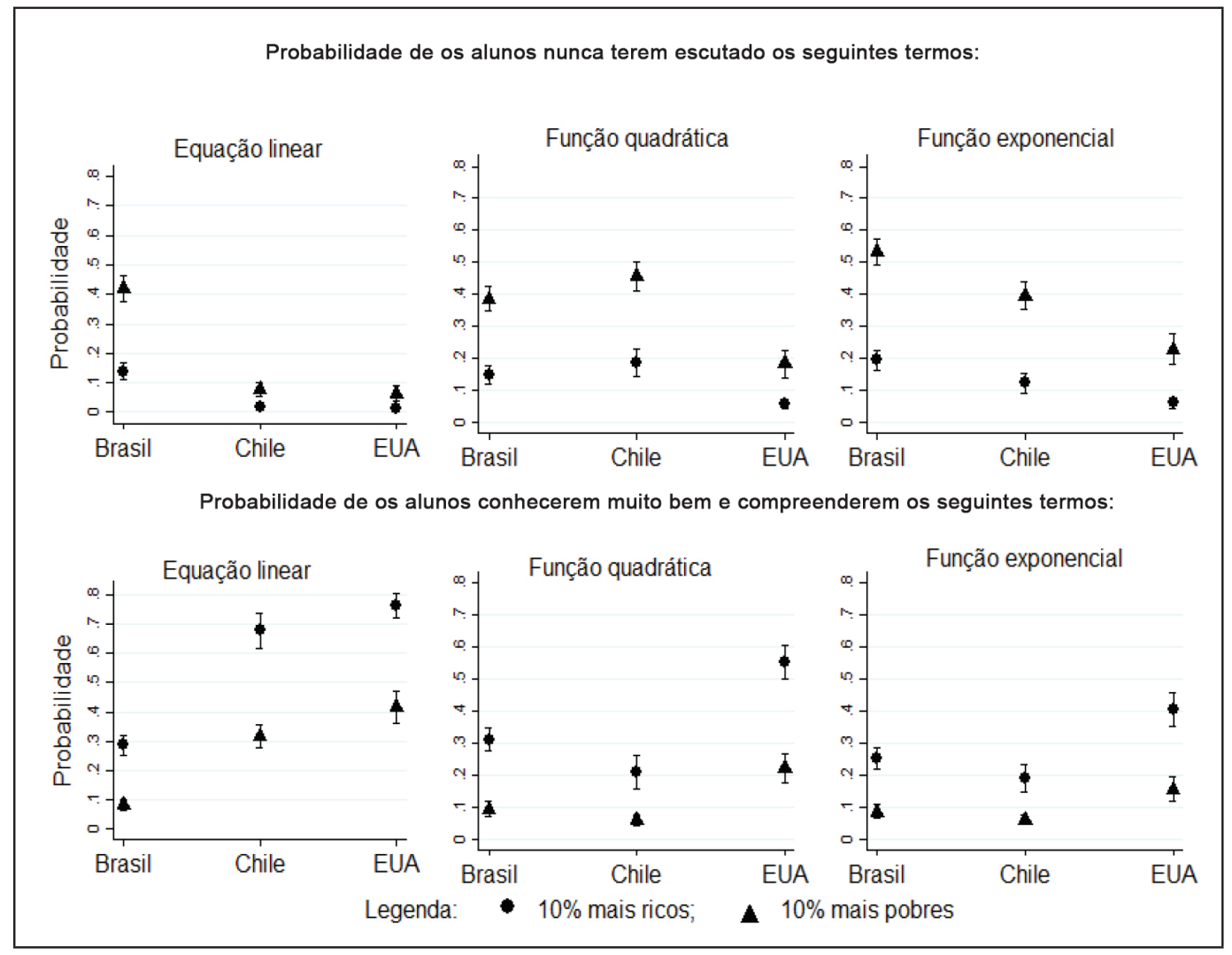

Fonte: Elaboração das autoras.

Além dos conceitos matemáticos, analisou-se a probabilidade de os alunos terem sido expostos a alguns tipos de problemas matemáticos ao longo de sua trajetória escolar (Gráfico 2). O questionário do PISA apresentou três equações e perguntou aos alunos o quanto foram expostos a problemas similares. Assim como no caso dos conceitos matemáticos, tais problemas apresentam diferentes graus de complexidade, sendo a equação de $1^{\circ}$ grau apresentada [ $\left.3 x+5=17\right]$ mais simples que a equação de $2^{\circ}$ grau $\left[6 x^{2}+5=29\right]$ que, por sua vez, é menos complexa que a também equação de $2^{\circ}$ grau $[2(x+3)=(x+3)(x-3)]$, já que essa última exige que o aluno resolva uma distribuição e ainda organize os termos antes de resolver a equação.

Praticamente todos os alunos, nos três países analisados, encontraram os três tipos de problemas matemáticos 
em algum momento da sua vida escolar, uma vez que a probabilidade de "nunca" terem visto qualquer uma das três equações é de aproximadamente $10 \%$, independentemente do nível socioeconômico (Gráfico 2, parte superior). Porém, quando analisamos a probabilidade de os alunos "frequentemente" encontrarem esses tipos de problemas em sua vida escolar, há disparidade entre os tipos de problemas, as classes sociais e os países (Gráfico 2, parte inferior).

GRÁFICO 2 - Probabilidade de exposição a problemas matemáticos da categoria Mudanças e Relações

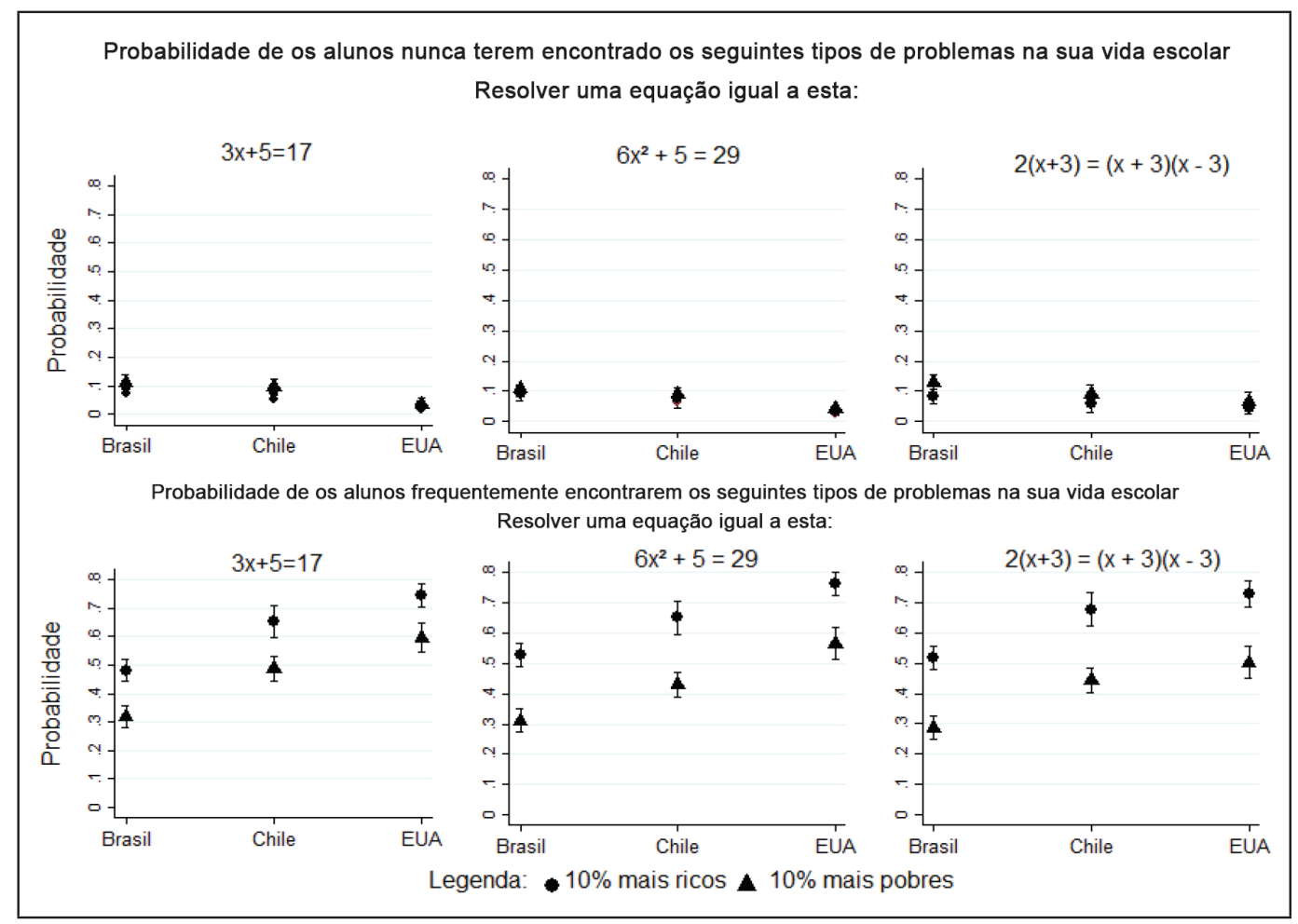

Fonte: Elaboração das autoras.

Os alunos brasileiros são os que menos encontraram com frequência os três tipos de equação em suas aulas. Além disso, há maior proximidade entre os ricos e pobres brasileiros, do que entre os ricos e pobres chilenos e estadunidenses. Ainda assim, nos três países, a diferença entre os níveis socioeconômicos aumenta à medida que os problemas apresentados 
tornam-se mais complexos. Por exemplo, o Gráfico 2 mostra que a diferença de probabilidade de os alunos ricos e pobres no Chile encontrarem com frequência uma equação de $1^{\circ}$ grau é de aproximadamente 10 pontos percentuais, mas é de quase 20 pontos percentuais para o terceiro tipo de equação mostrada. Essa tendência ocorre nos três países, na medida em que a probabilidade dos alunos ricos tende a se manter constante à medida que aumenta a complexidade dos problemas, enquanto a dos mais pobres diminui proporcionalmente à complexidade dos problemas apresentados.

Além disso, ainda que não haja praticamente desigualdade na inclusão desses conceitos e problemas nos currículos de matemática de todos os alunos nos três países (Gráfico 2, parte superior), há desigualdade entre os países na frequência com que esses problemas são apresentados (Gráfico 2, parte inferior). Entre os mais pobres, o Brasil é o que apresenta a menor probabilidade de seus alunos frequentemente encontrarem os três tipos de problemas. No caso dos alunos brasileiros mais ricos, a probabilidade de encontrarem esses problemas "com frequência” na sua vida escolar é menor ou igual à probabilidade dos alunos mais pobres no Chile e nos Estados Unidos.

\section{PROBABILIDADE DE ACESSO A CONCEITOS MATEMÁTICOS}

\section{DA CATEGORIA ESPAÇO E FORMA}

Na categoria Espaço e Forma, analisaram-se as probabilidades de os alunos serem expostos a quatro conceitos matemáticos pertencentes ao campo da geometria: (i) polígono; (ii) figura congruente; (iii) vetores; e (iv) cosseno. Dentre esses conceitos, é possível estabelecer relação entre os conceitos de polígonos e figuras congruentes, uma vez que, se dois polígonos tiverem ângulos e lados iguais, eles serão considerados figuras congruentes. Há, portanto, relação de complexidade entre polígono e figura congruente, na qual o segundo termo exige do aluno conhecimento mais profundo de geometria do que o primeiro. Levando essas informações em consideração, as análises a seguir irão detalhar, primeiramente, todos os resultados para os conceitos "polígono" e "figura congruente". Em seguida serão discutidos os resultados para os termos "vetores" e "cossenos". 
O Gráfico 3 mostra, como nos casos anteriores, que a probabilidade de os alunos nunca terem escutado um termo aumenta à medida que os termos ficam mais complexos, sendo tal aumento mais acentuado no Brasil. Além disso, a "brecha curricular" entre ricos e pobres também aumenta. Por exemplo, para ambas as classes sociais, há aumento no percentual de alunos que nunca aprenderam sobre "figura congruente" com respeito a "polígono": aumento de aproximadamente 10 pontos percentuais, entre os mais ricos, e 30 pontos percentuais, entre os mais pobres.

Seguindo esse movimento, a probabilidade de os alunos conhecerem muito bem e compreenderem um termo diminui quando o conceito torna-se mais complexo, embora tal queda seja menos acentuada para os três países. Quando se compara a probabilidade entre "polígono" e "figura congruente" - para o mesmo nível socioeconômico e país - a diferença é em torno de apenas 5 pontos percentuais.

Além disso, a diferença de exposição entre os países é alta, mesmo para conceitos menos complexos, como polígono. Por exemplo, os alunos mais ricos no Brasil têm a mesma probabilidade que os mais pobres no Chile e nos Estados Unidos de nunca terem escutado termos como "polígono" ou "figura congruente". Tal diferença permanece no caso de os alunos conhecerem bem e compreenderem um conceito: os alunos ricos no Brasil têm a mesma probabilidade estatística que os alunos pobres dos Estados Unidos de conhecerem os termos anteriormente mencionados. 


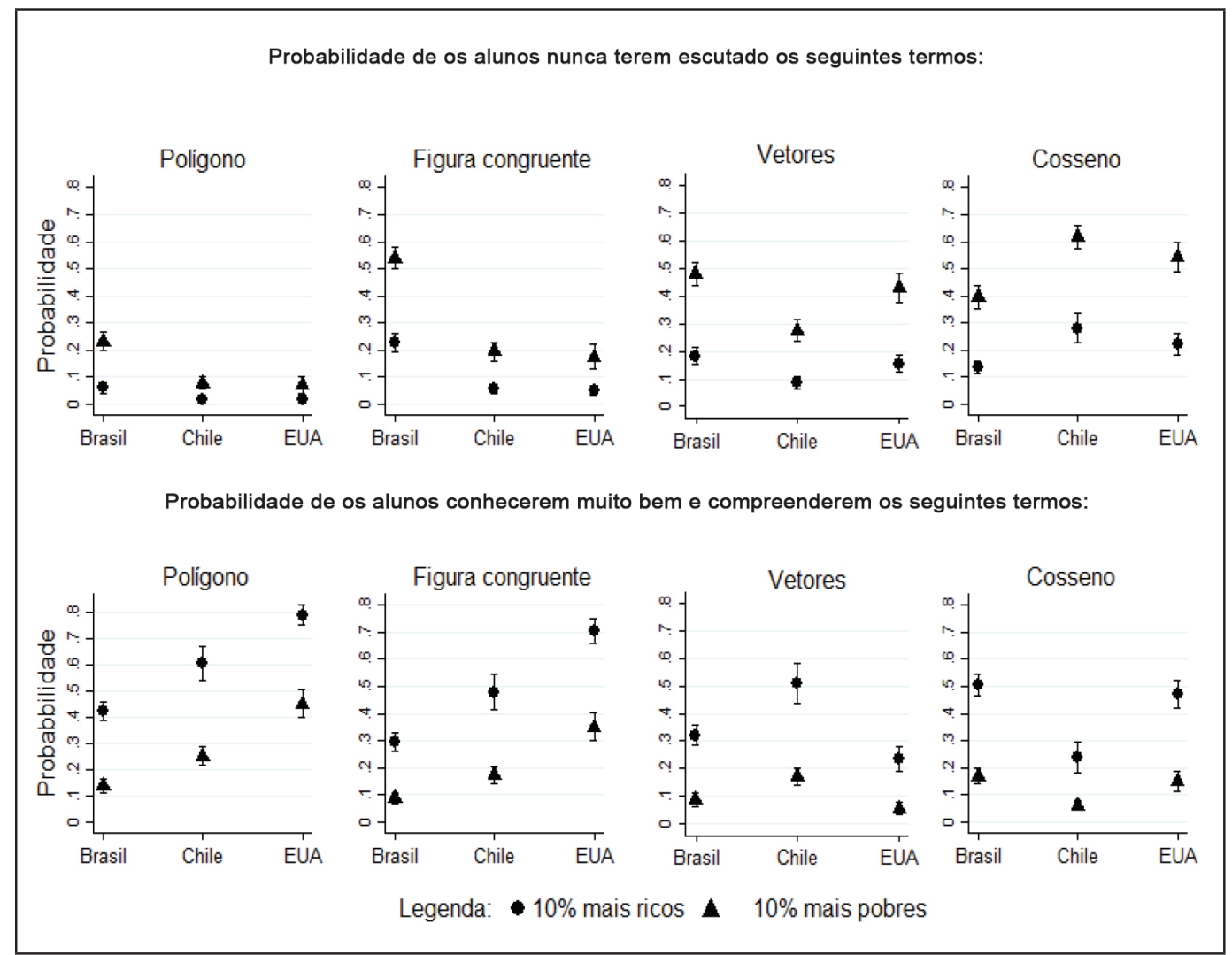

Fonte: Elaboração das autoras.

Já no caso dos termos "vetores" e "cosseno", o que chama atenção é a desigualdade entre os níveis socioeconômicos de um mesmo país e a alta probabilidade de os alunos pobres nunca terem escutado tais termos. Por exemplo, a probabilidade de os alunos pobres do Chile nunca terem escutado o termo cosseno é de aproximadamente $65 \%$. Além disso, a diferença entre os mais ricos e mais pobres nunca terem escutado cada um dos termos é em torno de $30 \%$ em todos os países analisados. O Brasil não apresenta a pior situação, mas tanto a probabilidade dos alunos pobres quanto a desigualdade entre os níveis socioeconômicos são altos.

A desigualdade permanece para o caso de os alunos conhecerem muito bem e compreenderem os conceitos de "vetores" e "cossenos", em todos os países. Por exemplo, entre 
os alunos pobres brasileiros, apenas $10 \%$ conhecem bem o termo "vetores" e, por volta de $20 \%$, o conceito "cosseno".

\section{PROBABILIDADE DE ACESSO A CONCEITOS MATEMÁTICOS}

\section{DA CATEGORIA QUANTIDADE}

Na categoria Quantidade, analisou-se a probabilidade ${ }^{9}$ de os alunos serem expostos a três conceitos matemáticos pertencentes a diferentes conjuntos numéricos: (i) radicais; (ii) números racionais; e (iii) números complexos. O termo radical é o mais simples e é o símbolo utilizado para representar a operação matemática radiciação. Além disso, geralmente os currículos costumam ensinar radicais antes dos números racionais que, por sua vez, vêm antes dos números complexos (em geral ensinados apenas no ensino médio, no caso do Brasil).

Nota-se, mais uma vez, que a probabilidade de os alunos conhecerem muito bem e compreenderem os conceitos diminui à medida que os termos tornam-se mais complexos. Isso é notório quando comparamos a probabilidade de entenderem "radicais" e "números racionais" de um lado e "números complexos" de outro. Por exemplo, enquanto os alunos mais ricos no Brasil têm probabilidade em torno de 50\% de conhecerem "radicais" e "números racionais", a porcentagem cai para apenas $20 \%$ no caso de "números complexos".

Em contrapartida, há diminuição na desigualdade entre os níveis socioeconômicos do mesmo país à medida que os conceitos tornam-se mais complexos, sendo essa queda mais acentuada para o Brasil. Enquanto a diferença entre pobres e ricos no Brasil era de aproximadamente $20 \%$ no caso de "radicais", é de menos de 10\% para "números complexos". O Gráfico 4 detalha essa diferença para todos os países e classes sociais.
9 Este artigo não irá analisar a probabilidade de os alunos "nunca terem escutado" os conceitos da categoria Quantidade, pois não são estatisticamente significativos. 


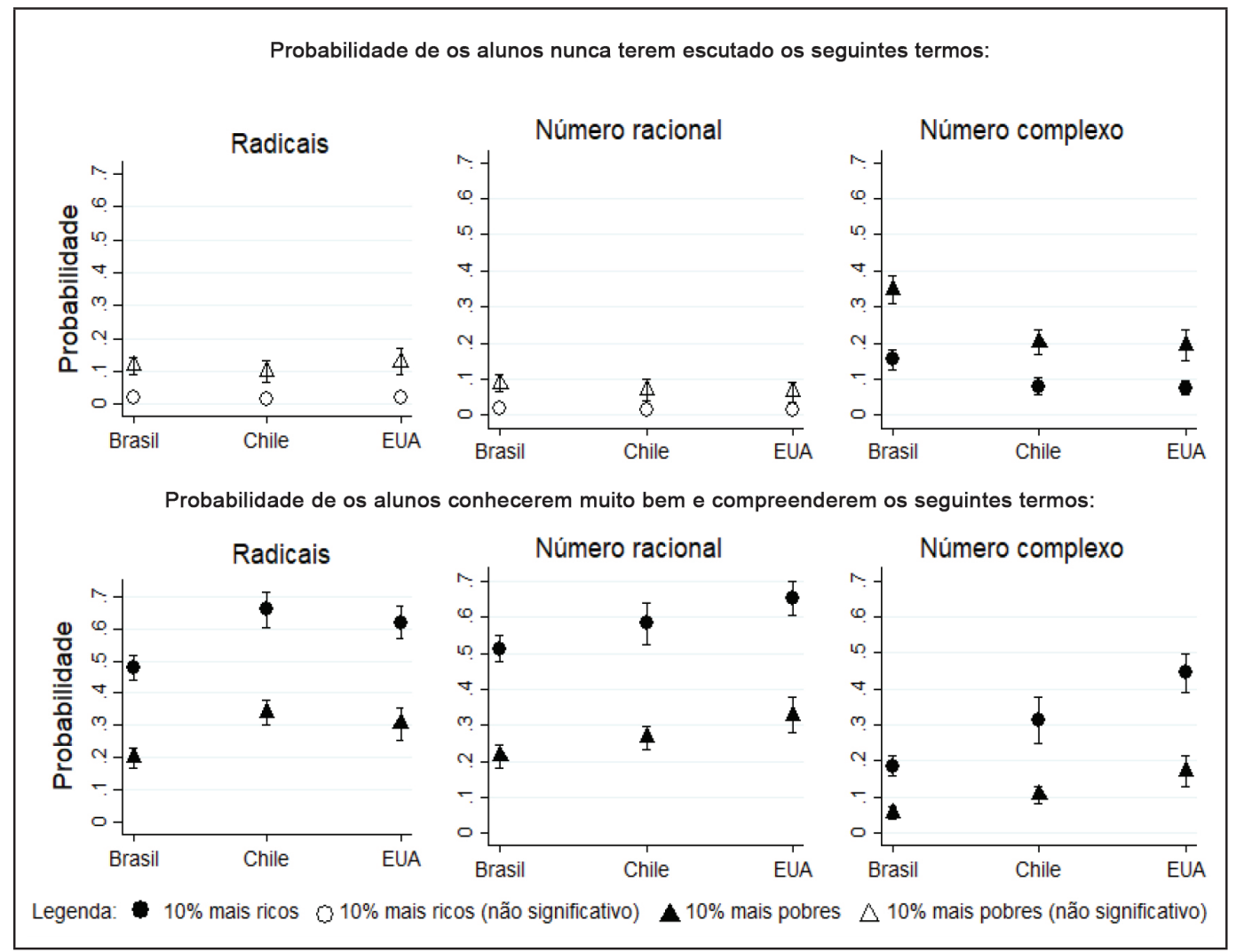

Fonte: Elaboração das autoras.

Embora a desigualdade entre os níveis socioeconômicos no Brasil seja a menor entre os três países, pode ser explicada pela baixa probabilidade de os alunos mais ricos, com respeito aos seus colegas de outros países, conhecerem bem tais termos. Por exemplo, um aluno rico brasileiro tem a mesma probabilidade que um aluno pobre dos Estados Unidos de conhecer bem o termo "números complexos".

\section{PROBABILIDADE DE ACESSO A CONCEITOS MATEMÁTICOS}

\section{DA CATEGORIA INCERTEZA E DADOS}

Na categoria Incerteza e Dados, analisou-se a probabilidade ${ }^{10}$

10 Este artigo irá comparar apenas os resultados estatisticamente significativos para os termos da categoria Incerteza e Dados. de os alunos serem expostos a dois conceitos matemáticos: (i) média aritmética e (ii) probabilidade. Ambos os termos pertencem ao campo da estatística e, ao contrário da maioria 
dos conceitos anteriormente analisados, tendem a estar mais presentes no cotidiano dos alunos.

GRÁFICO 5 - Probabilidade de exposição aos conceitos matemáticos da categoria Incerteza e Dados

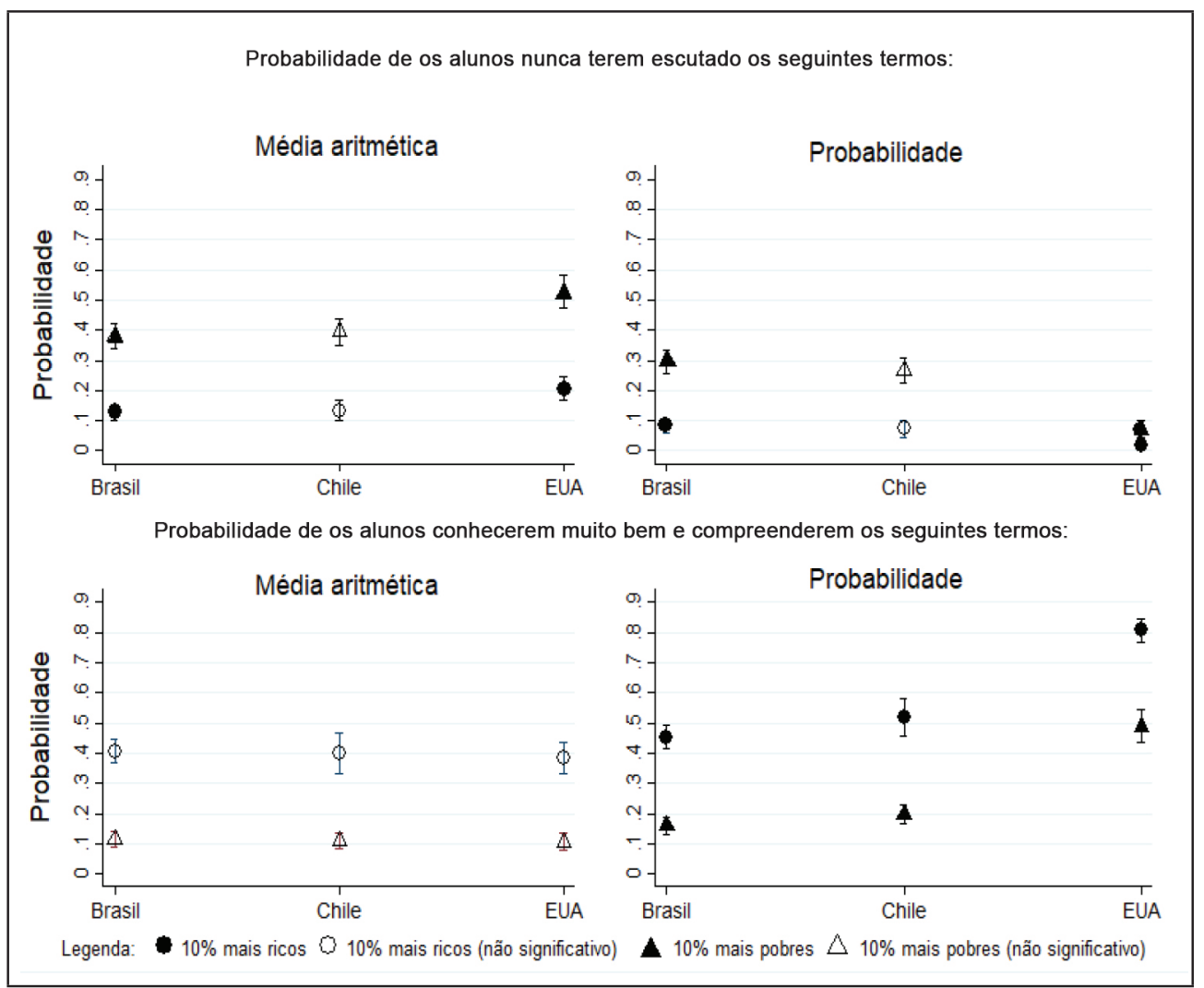

Fonte: Elaboração das autoras.

O que se destaca da análise dessa categoria é a grande desigualdade na probabilidade entre os países. Enquanto um aluno pobre no Brasil tem probabilidade em torno de $15 \%$ de conhecer bem e compreender o conceito de "probabilidade", nos Estados Unidos é de quase 50\% para a mesma classe social. Entre os alunos ricos brasileiros, a probabilidade é de $45 \%$, enquanto entre os alunos ricos dos Estados Unidos é de aproximadamente $80 \%$ (Gráfico 5).

Apesar de os termos média aritmética e probabilidade serem bastante conhecidos entre os alunos mais ricos do Brasil - somente $10 \%$ dizem não terem ouvido falar - menos 
11 HUSEN, Torsten et al. International study of achievement in mathematics, a comparison of twelve countries. International project for the evaluation of educational achievement IEA (Phase 1). Washington: ERIC Clearinghouse, 1967 de 50\% reportou compreender bem o termo. A situação é ainda mais grave entre os mais pobres, pois $70 \%$ ouviram falar de "probabilidade" nas aulas de matemática, mas menos de $20 \%$ sabe de fato o que isso significa.

\section{CONCLUSÃO}

Este artigo procurou medir as OTL em matemática de diferentes grupos sociais em três países participantes do PISA: Brasil, Chile e Estados Unidos. Dado que pesquisas empíricas no Brasil e no mundo têm mostrado forte correlação entre fatores relacionados à cobertura e exposição curricular e desempenho dos alunos (BOALER, 2001; CARNOY, 2003, 2007; LOUZANO, 2007; MCDONNELL, 1995; RIVKIN; SCHIMAN, 2015; SAMMONS, 1995; SIMIELLI, 2015), este estudo testou a relação entre os conceitos e problemas matemáticos analisados no PISA e os resultados dos estudantes nessa prova, para, em seguida, analisar a distribuição das OTL nesses três países. Nesse caso, buscou medir o conceito de OTL disseminado na literatura educacional desde o final dos anos 1970, a saber,

\section{[...] se alunos tiveram ou não oportunidades de aprender um tópico particular ou estudar como resolver um tipo específico de problema. (HUSEN et al., 1967, p. 162-163" apud BURSTEIN, 1993)}

Não é novidade os baixos resultados brasileiros em matemática no PISA. Na última edição da prova, a média dos Estados Unidos foi de 479 pontos e a do Chile, 423. O Brasil obteve apenas 377 pontos. Além disso, 70,2\% dos alunos brasileiros estão abaixo do nível 2 do PISA, o que significa que quase três quartos dos estudantes brasileiros não conseguem interpretar e reconhecer situações em contextos que não exigem mais do que inferência direta, extrair informações relevantes de uma única fonte e fazer uso de um único modo representacional, empregar algoritmos básicos, fórmulas, procedimentos ou convenções para resolver problemas envolvendo números inteiros e fazer interpretações literais dos resultados (OCDE, 2012). 
Em provas nacionais, como o Sistema de Avaliação da Educação Básica (Saeb), que avalia tópicos menos complexos e mede o desempenho em várias etapas da escolarização brasileira, os resultados não são positivos. Apenas $16 \%$ dos alunos no final do $9^{\circ}$ ano conseguem transformar uma fração em porcentagem. Portanto, tentar entender os fatores associados a esses resultados tem sido um dos objetivos da pesquisa educacional (CARNOY, 2007; LOUZANO, 2007).

Este artigo buscou mapear e analisar a distribuição das OTL dos nossos alunos vis-à-vis os alunos chilenos e estadunidenses, a fim de contribuir com o debate das políticas educacionais no Brasil, em especial aquelas relacionadas ao currículo. Uma perspectiva comparada nos permite analisar a distribuição de OTL em países com resultados em matemática melhores e mais equitativos que os do Brasil e assim buscar aprender seus processos e políticas. Nesse sentido, a escolha dos países seguiu uma lógica. O Chile é um país latino-americano com renda per capita e gasto educacional semelhantes ao Brasil. Em contrapartida, os Estados Unidos, ainda que tenham um gasto educativo muito superior, são um país federativo com grande diversidade e amplas desigualdades econômicas e sociais. Pesquisas internacionais comparadas de currículos de matemática apontam mais diferenças entre os países no que diz respeito à área de geometria do que de álgebra e aritmética (OECD, 2016). Os resultados apresentados aqui mostram que os estudantes brasileiros de ambos os estratos econômicos analisados têm baixa exposição curricular nas quatro categorias de conteúdos matemáticos avaliadas pelo PISA com respeito aos seus colegas no Chile e nos Estados Unidos. Por exemplo, os alunos mais ricos do Brasil têm a mesma probabilidade que os mais pobres no Chile e nos Estados Unidos de nunca terem escutado termos como "polígono" (por volta de $10 \%$ ) ou "figura congruente" (aproximadamente 20\%). A pesquisa também encontrou que a probabilidade de exposição a conceitos matemáticos tende a diminuir à medida que os conceitos matemáticos vão ficando mais complexos. A probabilidade de os alunos, nos três países, nunca terem escutado, durante sua trajetória escolar, o conceito "função 
exponencial" (mais complexo) é maior do que no caso do conceito "equação linear" (menos complexo). Seguindo a tendência, a probabilidade de os alunos responderem "conhecer muito bem e compreender" um conceito diminui quanto mais complexo é o conceito matemático.

No entanto, no Brasil, essa diferença tende a ser menor que no Chile e nos Estados Unidos, pois o ponto inicial compreensão de conceitos menos complexos, como equação linear - já é bastante baixo quando comparado com os outros dois países. No Chile e nos Estados Unidos, as dificuldades dos alunos em matemática tendem a estar concentradas na transição de conceitos mais simples aos mais complexos, tanto no que diz respeito à exposição a esses conceitos como à sua compreensão. $\mathrm{O}$ caso brasileiro mostra que o déficit na exposição e compreensão de conceitos matemáticos pode residir em conceitos muito mais simples que os medidos pela prova PISA. Portanto, os professores dos alunos participantes do PISA podem estar optando por não ensinar determinados conceitos, até os mais simples, pelo fato de seus alunos não dominarem conceitos relativamente básicos da matemática que permitiriam resolver os problemas propostos para a série. Para compreender em que medida isso reflete uma opção docente ou o próprio currículo pretendido, seria preciso seguir a metodologia proposta por Zakaryan (2011). O autor inicialmente analisa se o currículo prescrito nos documentos oficiais contém os conteúdos adequados e, em seguida, observa se o currículo implementado em sala de aula cobre realmente todos os pontos pretendidos e em que profundidade. O desenho do PISA não permite que façamos esse tipo de análise, uma vez que os currículos oficiais dos países não são utilizados.

Os resultados apresentados aqui também mostram que a diferença entre ricos e pobres tende a ser maior à medida que os conceitos matemáticos tornam-se mais complexos, mostrando que a "brecha curricular" tende a se intensificar. No caso brasileiro, a brecha entre ricos e pobres já é grande mesmo se tratando de conceitos simples. Por exemplo, enquanto nos Estados Unidos e no Chile é igual a probabilidade de alunos ricos e pobres nunca terem escutado o termo "equação linear" 
(aproximadamente 7\%), a diferença entre alunos ricos e pobres nos Estados Unidos sobe para aproximadamente 20 pontos percentuais e, no Chile, para mais de 30 pontos percentuais, no caso de "função exponencial". No Brasil, a diferença entre alunos ricos e pobres que nunca escutaram o termo "equação linear" já é bastante alta, em torno de 25 pontos percentuais, chegando a quase 30 pontos percentuais no caso de "função exponencial". Haberman (1991) referiu-se ao fenômeno de oferecer às crianças negras e pobres estadunidenses, concentradas em escolas urbanas, um currículo simplificado com atividades menos complexas e de simples resolução como "pedagogia da pobreza”. Para o autor, a opção por um currículo menos rigoroso para os mais pobres é parte importante da explicação sobre os baixos resultados estadunidenses, mas também das grandes diferenças na aprendizagem dos alunos de diferentes grupos sociais no país.

Este artigo também comparou as respostas dos alunos com respeito a "ter sido exposto ao conceito" e "compreender bem o conceito". A diferença nas respostas dos alunos nessas duas questões para o mesmo conteúdo mostra que há disparidades profundas nos três países, particularmente maiores no Brasil. Por exemplo, embora a probabilidade de um aluno rico brasileiro nunca ter escutado o termo "equação linear" não seja tão alta (próximo a 10\%), apenas 30\% dos alunos mais ricos "conhecem bem" esse termo.

A menor desigualdade nas OTL no Brasil entre ricos e pobres, quando comparado aos demais países, mais do que ser considerada uma boa notícia, é reveladora de nossa debilidade, uma vez que tanto estudantes brasileiros ricos como pobres têm baixa exposição e baixa compreensão sobre uma gama de conceitos matemáticos.

Este estudo revelou que não só não há igualdade de oportunidades entre ricos e pobres no Brasil com respeito ao currículo, mas que, mesmo entre os mais ricos, as oportunidades de aprender são bem menores que em outros países. Portanto, o debate curricular em curso em nosso país pode beneficiar-se de alguns achados deste estudo. Fica patente a necessidade de aumentar a exposição de nossos alunos a um currículo mais rigoroso e desafiador na área de matemática. 
Dominar essa linguagem não só amplia as possibilidades profissionais de nossos alunos como contribui para o exercício de sua cidadania e para o desenvolvimento econômico e social do país. O estudo comparado de Stevenson e Stigler (1992) mostra que, no Japão, o acesso a um currículo rigoroso e uniforme para todos, em comparação com o currículo menos homogêneo e com as OTL distribuídas segundo cor/ raça e nível socioeconômico nos Estados Unidos, explica os bons resultados dos japoneses e os baixos resultados dos estadunidenses em matemática.

Portanto, precisamos criar políticas e mecanismos para garantir que as oportunidades de aprender matemática sejam compartilhadas entre todos, sob pena de que um aumento da excelência traga ainda mais desigualdade. Pesquisas comparadas e/ou estudos de caso que busquem analisar as políticas curriculares e seus impactos, nacionais e internacionais, podem trazer importantes contribuições ao nosso debate.

\section{REFERÊNCIAS}

BOALER, Jo. Mathematical modelling and new theories of learning. Teaching Mathematics and its Applications, v. 20, n. 3, p. 121-128, 2001.

BURSTEIN, Leigh. Studying learning, growth, and instruction cross-nationally: lessons learned about why and why not engage in cross-national studies. In: BURSTEIN, Leigh. The IEA study of mathematics III: student growth and classroom processes. Oxford: Pergamon, 1993. p. 27-49.

CARNOY, Martin. Cuba's academic advantage: why students in Cuba do better in school. Stanford: Stanford University Press, 2007.

CARNOY, Martin; GOVE, Amber; MARSHALL, Jeffery. Explaining differences in academic achievement in Latin America: qualitative evidence from Brazil, Chile and Cuba. Stanford: Stanford University, 2003. Mimeografado.

CARROLL, John. A model of school learning. The Teachers College Record, v. 64, n. 8, p. 723-723, 1963.

EVERTSON, Carolyn M. et al. Improving classroom management: an experiment in elementary school classrooms. The Elementary School Journal, v. 84, n. 2, p. $172-188,1983$.

HABERMAN, Martin. The pedagogy of poverty versus good teaching. Phi Delta Kappan, v. 73, n. 4, p. 290-294, dec. 1991. 
HERMAN, Joan L.; KLEIN, Davina C. D.; ABEDI, Jamal. Assessing students' opportunity to learn: teacher and student perspectives. Educational Measurement: Issues and Practice, v. 19, n. 4, p. 16-24, 2000.

HIEBERT, James; GROUWS, Douglas A. The effects of classroom mathematics teaching on students' learning. In: LESTER, Frank (Ed.). Second handbook of research on mathematics teaching and learning. Charlotte: Information Age Publishing, 2007. p. 371-404.

LOUZANO, Paula. Do schools matter in Brazil? Excellence and equity in Brazilian primary education. Cambridge: Harvard University, 2007.

MACCINI, Paula; GAGNON, Joseph Calvin. Best practices for teaching mathematics to secondary students with special needs: implications from teacher perceptions and a review of the literature. Focus on Exceptional Children, v. 32, n. 5, p. 1-22, 2000.

MCDONNELL, Lorraine M. Opportunity to learn as a research concept and a policy instrument. Educational Evaluation and Policy Analysis, v. 17, n. 3, p. 305-322, 1995.

MULLENS, John E. et al. Measuring classroom instructional processes: using survey and case study field test results to improve item construction. Washington: U. S. Department of Education, National Center for Education Statistics, 1999. (Working Paper Series, 8).

ORGANISATION FOR ECONOMIC CO-OPERATION AND DEVELOPMENT. PISA 2014 results: what students know and can do: student performance in reading, mathematics and science. Paris: OECD, 2014. v. 1.

ORGANISATION FOR ECONOMIC CO-OPERATION AND DEVELOPMENT. Equations and inequalities: making mathematics accessible to all. PISA. Paris: OECD Publishing, 2016. Disponível em: <http://dx.doi. org/10.1787/9789264258495-en>. Acesso em: 5 mar. 2017.

PEÑA-LÓPEZ, Ismael et al. PISA 2012: assessment and analytical framework. Mathematics, reading, science, problem solving and financial literacy. Paris: OECD Publishing, 2012.

PIACENTINI, Mario; MONTICONE, Chiara. Equations and inequalities: making mathematics accessible to all. PISA. Paris: OECD Publishing, 2016.

PORTER, Andrew C. Curriculum reform and measuring what is taught: measuring the quality of education processes. In: ANNUAL MEETING OF THE ASSOCIATION FOR PUBLIC POLICY ANALYSIS AND MANAGEMENT. New York, 1998.

PORTER, Andrew C. et al. Reform up close: an analysis of high school mathematics and science classrooms. Final report. Washington: ERIC Clearinghouse, 1993.

PORTER, Andrew C. et al. Does professional development change teaching practice? Results from a three-year study. Washington: ERIC Clearinghouse, 2000.

RAY, Adams; MARGARET, Wu (Ed.). PISA 2000 technical report. Paris: OECD Publishing, 2002. 
RIVKIN, Steven G.; SCHIMAN, Jeffrey C. Instruction time, classroom quality, and academic achievement. The Economic Journal, v. 125, n. 588, p. 425-448, 2015.

ROBITAILLE, David F. Students' achievements: population A, 1988. In: ROBITAILLE David F.; GARDEN Robert A. The IEA study of mathematics II: contexts and outcomes of school mathematics. Oxford: Pergamon, 1989.

ROWAN, Brian; CAMBURN, Eric; CORRENTI, Richard. Using teacher logs to measure the enacted curriculum in large-scale surveys: insights from the study of instructional improvement. Elementary School Journal, v. 105, p. 75-102, 2004.

SAMMONS, Pam et al. Key characteristics of effective schools: a review of school effectiveness research. Ringwood: B \& MBC Distribution Services, 1995.

SCHMIDT, William H. High school course-taking: its relationship to achievement. Journal of Curriculum Studies, v. 15, n. 3, p. 311-332, 1983.

SCHMIDT, William H.; Maier, Adam. Opportunity to learn. In: SYKES Gary; SCHNEIDER Barbara; PLANK David N. (Ed.). Handbook of education policy research. New York: Routledge, 2009. p. 541-559.

SCHMIDT, William H. et al. Why schools matter: a cross-national comparison of curriculum and learning. San Francisco: The Jossey-Bass Education Series, 2001.

SIMIELLI, Lara Elena Ramos. Equidade educacional no Brasil: análise das oportunidades educacionais em 2001 e 2011. 2015. Tese (Doutorado) Fundação Getúlio Vargas, Rio de Janeiro, 2015.

STEEN, Lynn Arthur. On the shoulders of giants: new approaches to numeracy. Washington: National Academy Press, 1990.

STEVENSON, Harold; STIGLER, James W. Learning gap: why our schools are failing and what we can learn from Japanese and Chinese education. New York: Touchstone, 1992.

ZAKARYAN, Diana et al. Oportunidades de aprendizaje y competencias matemáticas de estudiantes de 15 años: un estudio de casos. Huelva: Universidad de Huelva, 2011.

\section{PAULA LOUZANO}

Pesquisadora visitante da Stanford University, Stanford, Califórnia, Estados Unidos da América

paula.louzano@gmail.com

\section{ARIANE FARIA DOS SANTOS}

Mestranda da Universidade de São Paulo (USP), São Paulo, São Paulo, Brasil arianefariadossantos@gmail.com 


\section{APÊNDICE}

REGRESSÃO MULTIVARIADA

A seguir estão descritas as especificações da regressão multivariada utilizada no presente artigo:

$$
y_{i}=\beta_{0}+\beta_{1} \text { Chile }_{i}+\beta_{2} \text { EUA }_{i}+\beta_{3} \text { socioeco }_{i}+X^{\prime} \beta+\varepsilon_{i},
$$

onde: $y_{i}=$ Proficiência em Matemática no PISA 2012 do indivíduo $i$;

Chile $_{i}=$ Variável dummy que indica se o indivíduo $i$ reside no Chile;

$E U A_{i}=$ Variável dummy que indica se o indivíduo $i$ reside nos Estados Unidos;

socioeco $_{i}=$ Nível socioeconômico do indivíduo $i$;

$X^{\prime}=$ Vetor de variáveis dummy que inclui todos os conceitos de matemática;

$\varepsilon_{i}=$ Erro do modelo.

Por sua vez, a Tabela 1 apresenta os resultados da regressão: 
TABELA 1 - Regressão multivariada: análise da relação entre a proficiência no PISA 2012 e alguns conceitos e problemas matemáticos

\begin{tabular}{|c|c|c|}
\hline $\begin{array}{l}\text { VARIÁVEIS INDEPENDENTES } \\
\text { (NUNCA TER TIDO CONTATO COM OS SEGUINTES } \\
\text { TERMOS E PROBLEMAS MATEMÁTICOS) }\end{array}$ & COEFICIENTE & ERRO PADRÃO \\
\hline Nível socioeconômico & $24.530^{* * *}$ & $(1.295)$ \\
\hline \multicolumn{3}{|l|}{ Países } \\
\hline Chile & $15.861^{* * *}$ & $(3.411)$ \\
\hline EUA & $49.784^{* * *}$ & $(4.001)$ \\
\hline \multicolumn{3}{|l|}{ Mudanças e relações } \\
\hline Equação linear & -1.055 & $(3.274)$ \\
\hline Função quadrática & $-5.409^{* *}$ & $(2.741)$ \\
\hline Função exponencial & $-17.393^{* * *}$ & $(2.882)$ \\
\hline Resolver uma equação igual a esta: $3 x+5=17$ & -5.734 & $(5.309)$ \\
\hline Resolver uma equação igual a esta: $6 x^{2}+5=29$ & $-16.511^{* *}$ & $(6.437)$ \\
\hline Resolver uma equação igual a esta: $2(x+3)=(x+3)(x-3)$ & -5.327 & $(5.614)$ \\
\hline \multicolumn{3}{|l|}{ Espaço e forma } \\
\hline Vetores & $-14.068^{* * *}$ & (3.053) \\
\hline Cosseno & $-30.491^{* * *}$ & (3.428) \\
\hline Polígono & -6.975 & $(4.970)$ \\
\hline Figura congruente & 2.004 & $(2.568)$ \\
\hline \multicolumn{3}{|l|}{ Quantidade } \\
\hline Radicais & $-18.439 * * *$ & $(4.888)$ \\
\hline Número racional & -2.453 & $(8.498)$ \\
\hline Número complexo & $19.396^{* * *}$ & $(2.807)$ \\
\hline \multicolumn{3}{|l|}{ Incerteza e dados } \\
\hline Média aritmética & $-7.655^{* *}$ & $(3.138)$ \\
\hline Probabilidade & $-20.548^{* * *}$ & $(3.658)$ \\
\hline Constante & $455.843^{* * *}$ & (2.807) \\
\hline
\end{tabular}

Fonte: Elaboração das autoras

MODELO LOGIT

As características dos modelos logit utilizados neste artigo estão descritas a seguir:

$$
L_{i}=\ln \left(P_{i} / 1-P_{i}\right)=Z_{i}=\beta_{0}+\beta_{1} X_{1 i}+\beta_{2} X_{2 i}+\varepsilon_{i},
$$

onde: $P_{i}=$ Probabilidade de acesso a algum tipo de conceito matemático ao longo de sua trajetória escolar;

$X_{j i}=$ Características dos estudantes (1= Nível Socioeconômico; 2 = País). 
As tabelas 2, 3, 4 e 5 apresentam os resultados para todos os modelos logit construídos, para cada categoria de conteúdo matemático: Espaço e Forma, Mudanças e Relações, Quantidade e Incerteza e Dados. O Brasil, assim como os 10\% mais ricos, foi utilizado como parâmetro de comparação. Os números entre parênteses representam o erro padrão e os fora dos parênteses, coeficientes que significam quantas vezes as demais categorias têm chance de terem sido expostas aos conceitos/problemas matemáticos em comparação aos $10 \%$ mais ricos do Brasil. Por exemplo, um aluno do Chile tem 0,417 vezes de chance de "nunca ter escutado o termo vetor" quando comparado a um aluno pobre do Brasil. Por fim, os coeficientes desta tabela foram utilizados para construir as probabilidades de exposição aos conceitos e problemas matemáticos analisados neste artigo.

TABELA 2 - Resultado modelo Logit para a categoria Espaço e Forma - em odds ratio

\begin{tabular}{|c|c|c|c|c|c|c|c|c|c|c|}
\hline \multirow{2}{*}{\multicolumn{2}{|c|}{ ESPAÇO E FORMA }} & \multirow{2}{*}{\multicolumn{2}{|c|}{ CHILE }} & \multirow{2}{*}{\multicolumn{2}{|c|}{ EUA }} & \multirow{2}{*}{\multicolumn{2}{|c|}{$\begin{array}{l}\text { 10\% MAIS } \\
\text { POBRES }\end{array}$}} & \multicolumn{2}{|c|}{ CONSTANTE } & \multirow{2}{*}{$\begin{array}{c}\mathbf{N} \\
3927\end{array}$} \\
\hline & & & & & & & & & & \\
\hline \multirow{2}{*}{ Vetores } & $\begin{array}{l}\text { Nunca escutei o } \\
\text { termo }\end{array}$ & $\frac{\text { COEF. }}{0.417^{* * *}}$ & $\begin{array}{c}\text { E.P. } \\
(0.053)\end{array}$ & $\frac{\text { COEF. }}{0.819^{*}}$ & $\begin{array}{c}\text { E.P. } \\
(0.098)\end{array}$ & $\begin{array}{c}\text { COEF. } \\
4.082^{* * *}\end{array}$ & $\begin{array}{c}\text { E.P. } \\
(0.535)\end{array}$ & $\begin{array}{c}\text { COEF. } \\
0.225^{* * *}\end{array}$ & $\frac{\text { E.P. }}{(0.024)}$ & \\
\hline & $\begin{array}{l}\text { Conheço o termo } \\
\text { muito bem }\end{array}$ & $2.188^{* * *}$ & $(0.299)$ & $0.647^{* * *}$ & $(0.094)$ & $0.201^{* * *}$ & $(0.036)$ & $0.473^{* * *}$ & $(0.040)$ & 3927 \\
\hline \multirow{2}{*}{ Cosseno } & $\begin{array}{l}\text { Nunca escutei o } \\
\text { termo }\end{array}$ & $2.459^{* * *}$ & $(0.283)$ & $1.813^{* * *}$ & $(0.212)$ & $4.143^{* * *}$ & $(0.543)$ & $0.158^{* * *}$ & $(0.017)$ & 3923 \\
\hline & $\begin{array}{l}\text { Conheço o termo } \\
\text { muito bem }\end{array}$ & $0.310^{* * *}$ & $(0.048)$ & 0.877 & $(0.104)$ & $0.200^{* * *}$ & $(0.028)$ & 1.020 & $(0.081)$ & 3923 \\
\hline \multirow{2}{*}{ Polígono } & $\begin{array}{l}\text { Nunca escutei o } \\
\text { termo }\end{array}$ & $0.284^{* * *}$ & $(0.053)$ & $0.254^{* * *}$ & $(0.062)$ & $4.747^{* * *}$ & $(0.904)$ & $0.064^{* * *}$ & $(0.011)$ & 3935 \\
\hline & $\begin{array}{l}\text { Conheço o termo } \\
\text { muito bem }\end{array}$ & $2.098^{* * *}$ & $(0.272)$ & $5.123^{* * *}$ & $(0.626)$ & $0.219^{* * *}$ & $(0.029)$ & $0.736^{* * *}$ & $(0.058)$ & 3935 \\
\hline \multirow{2}{*}{$\begin{array}{l}\text { Figura } \\
\text { congruente }\end{array}$} & $\begin{array}{l}\text { Nunca escutei o } \\
\text { termo }\end{array}$ & $0.206^{* * *}$ & $(0.028)$ & $0.182^{* * *}$ & $(0.027)$ & $4.020^{* * *}$ & $(0.508)$ & $0.292^{* * *}$ & $(0.029)$ & 3939 \\
\hline & $\begin{array}{l}\text { Conheço o termo } \\
\text { muito bem }\end{array}$ & $2.216^{* * *}$ & $(0.292)$ & $5.740^{* * *}$ & (0.709) & $0.228^{* * *}$ & $(0.033)$ & $0.414^{* * *}$ & $(0.035)$ & 3939 \\
\hline
\end{tabular}

Fonte: Elaboração das autoras. 
TABELA 3 - Resultado modelo Logit para a categoria Mudanças e Relações - em odds ratio

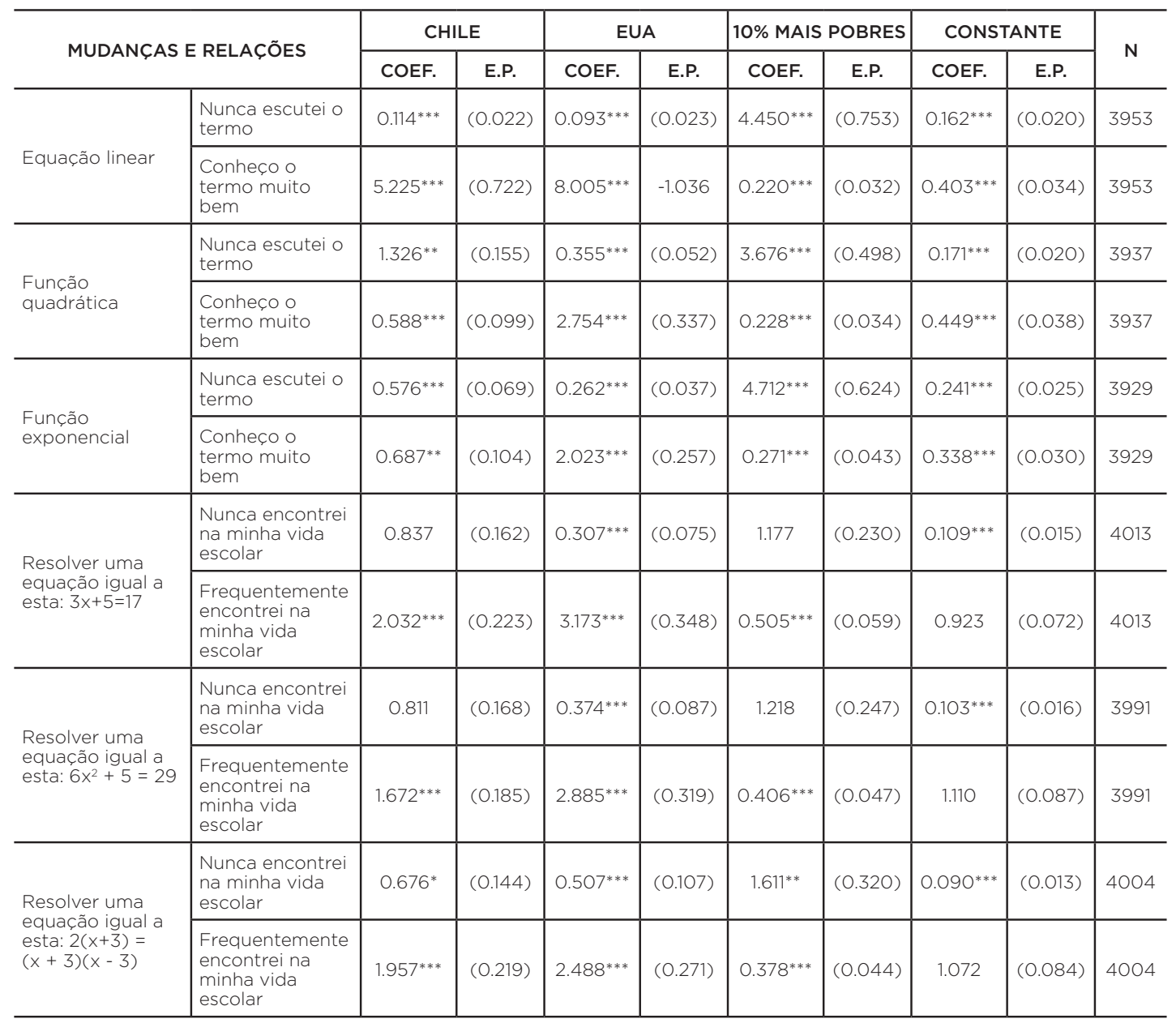

Fonte: Elaboração das autoras. 
TABELA 4 - Resultado modelo Logit para a categoria Quantidade - em odds ratio

\begin{tabular}{|c|c|c|c|c|c|c|c|c|c|c|}
\hline \multirow{2}{*}{\multicolumn{2}{|c|}{ QUANTIDADE }} & \multicolumn{2}{|c|}{ CHILE } & \multicolumn{2}{|c|}{ EUA } & \multicolumn{2}{|c|}{$\begin{array}{l}10 \% \text { MAIS } \\
\text { POBRES }\end{array}$} & \multicolumn{2}{|c|}{ CONSTANTE } & \multirow{2}{*}{$\mathbf{N}$} \\
\hline & & COEF. & E.P. & COEF. & E.P. & COEF. & E.P. & COEF. & E.P. & \\
\hline \multirow{2}{*}{ Radicais } & $\begin{array}{l}\text { Nunca escutei o } \\
\text { termo }\end{array}$ & 0.846 & $(0.190)$ & 1.118 & $(0.226)$ & $6.742^{* * *}$ & -1.753 & $0.020^{* * *}$ & $(0.005)$ & 3929 \\
\hline & $\begin{array}{l}\text { Conheço o termo } \\
\text { muito bem }\end{array}$ & $2.086^{* * *}$ & $(0.243)$ & $1.762^{* * *}$ & $(0.198)$ & $0.269^{* * *}$ & $(0.034)$ & 0.925 & $(0.072)$ & 3929 \\
\hline \multirow{2}{*}{$\begin{array}{l}\text { Número } \\
\text { racional }\end{array}$} & $\begin{array}{l}\text { Nunca escutei o } \\
\text { termo }\end{array}$ & 0.793 & $(0.211)$ & 0.707 & $(0.182)$ & $5.464^{* * *}$ & -1.588 & $0.018^{* * *}$ & $(0.005)$ & 3987 \\
\hline & $\begin{array}{l}\text { Conheço o termo } \\
\text { muito bem }\end{array}$ & $1.323^{* *}$ & $(0.147)$ & $1.794^{* * *}$ & $(0.200)$ & $0.259^{* * *}$ & $(0.032)$ & 1.054 & $(0.082)$ & 3987 \\
\hline \multirow{2}{*}{$\begin{array}{l}\text { Número } \\
\text { complexo }\end{array}$} & $\begin{array}{l}\text { Nunca escutei o } \\
\text { termo }\end{array}$ & $0.476^{* * *}$ & $(0.064)$ & $0.451^{* * *}$ & $(0.064)$ & $2.942^{* * *}$ & $(0.406)$ & $0.182^{* * *}$ & $(0.020)$ & 3927 \\
\hline & $\begin{array}{l}\text { Conheço o termo } \\
\text { muito bem }\end{array}$ & $2.009^{* * *}$ & $(0.311)$ & $3.516^{* * *}$ & $(0.457)$ & $0.260^{* * *}$ & $(0.043)$ & $0.228^{* * *}$ & $(0.021)$ & 3927 \\
\hline
\end{tabular}

Fonte: Elaboração das autoras.

TABELA 5 - Resultado modelo Logit para a categoria Incerteza e Dados - em odds ratio

\begin{tabular}{|c|c|c|c|c|c|c|c|c|c|c|}
\hline \multicolumn{2}{|c|}{ INCERTEZA E DADOS } & \multicolumn{2}{|c|}{ CHILE } & \multicolumn{2}{|c|}{ EUA } & \multicolumn{2}{|c|}{$\begin{array}{l}10 \% \text { MAIS } \\
\text { POBRES }\end{array}$} & \multicolumn{2}{|c|}{ CONSTANTE } & \multirow{2}{*}{$\mathrm{N}$} \\
\hline & & COEF. & E.P. & COEF. & E.P. & COEF. & E.P. & COEF. & E.P. & \\
\hline \multirow{2}{*}{$\begin{array}{l}\text { Média } \\
\text { aritmética }\end{array}$} & $\begin{array}{l}\text { Nunca escutei o } \\
\text { termo }\end{array}$ & 1.062 & $(0.129)$ & $1.807^{* * *}$ & $(0.213)$ & $4.251^{* * *}$ & $(0.564)$ & $0.144^{* * *}$ & $(0.016)$ & 3942 \\
\hline & $\begin{array}{l}\text { Conheço o termo } \\
\text { muito bem }\end{array}$ & 0.966 & $(0.137)$ & 0.900 & (0.113) & $0.190^{* * *}$ & $(0.029)$ & $0.687^{* * *}$ & $(0.055)$ & 3942 \\
\hline \multirow{2}{*}{ Probabilidade } & $\begin{array}{l}\text { Nunca escutei o } \\
\text { termo }\end{array}$ & 0.871 & $(0.121)$ & $0.181^{* * *}$ & $(0.044)$ & $4.633^{* * *}$ & $(0.945)$ & $0.091^{* * *}$ & $(0.015)$ & 3971 \\
\hline & $\begin{array}{l}\text { Conheço o termo } \\
\text { muito bem }\end{array}$ & $1.309^{* *}$ & $(0.156)$ & $5.028^{* * *}$ & $(0.610)$ & $0.230^{* * *}$ & $(0.030)$ & $0.831^{* *}$ & $(0.065)$ & 3971 \\
\hline
\end{tabular}

Fonte: Elaboração das autoras. 